\title{
*tobis
}

14. TESENA

DEL POPÚLISMO PENAL A LA PUNITIVIDAD: LA POLITICA

PENAL EN COLOMBIAEN EL SIGLO XXI

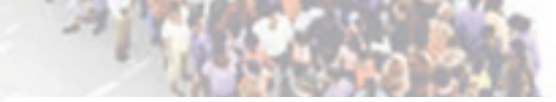

Alejandra Hernández C. is in 1
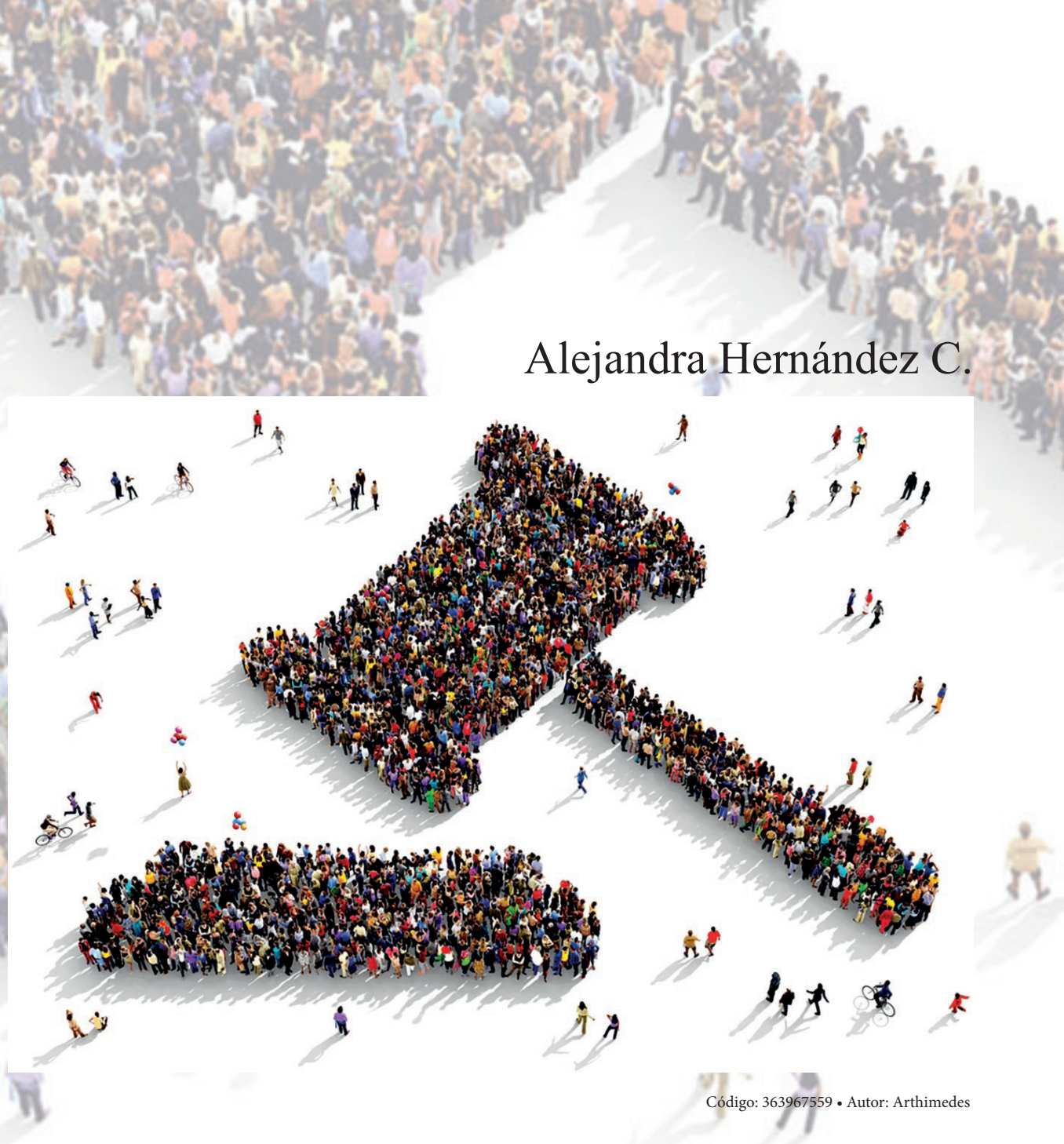



\title{
RESEÑA
}

\section{DEL POPULISMO PENAL A LA PUNITIVIDAD: LA POLÍTICA PENAL EN COLOMBIA EN EL SIGLO XXI}

\author{
Velandia Montes, Rafael \\ Bogotá, Universidad Católica de Colombia \\ 2017,78 P.
}

A lo largo de la historia, el populismo se ha definido como aquel fenómeno generador de disgustos políticos en todo el mundo, ya que crea situaciones de inseguridad y criminalidad, lo que pone en riesgo los intereses jurídicos implicados. Esto trae como consecuencia altos costos políticos sin que haya algún beneficio para ciertos grupos a los cuales se les manipulan intereses propios.

Seguido de esto se encuentra el populismo penal, un campo de políticas públicas en el que se intenta persuadir y ejecutar propuestas mediante varias medidas de acción. Este tipo de populismo se especializa en el problema de género, a partir de que las mujeres han estado en posición de víctimas frente al machismo, por ser violentadas con tratos indebidos y ser vistas como inferiores al hombre. Por estas y otras razones se puede considerar la acción práctica del populismo en estos casos específicos.

En situaciones de abuso sexual, acoso laboral, ataques con ácido y otros actos contra la mujer se pretenderá a toda costa defender los derechos y obtener las reparaciones a los daños causados. En primer lugar, se trata la definición de feminicidio, sus implicaciones y su relación con la legislación.

La investigación parte del desarrollo de la política en Colombia en el siglo XXI y resalta dos casos especiales: el epicentro de la evolución normativa de los casos de 
feminicidio y los ataques con agentes químicos. Se concretan los conceptos de los ataques, tras un análisis de la Ley 1761 de 2015 y la Ley 1773 de 2016, las cuales establecieron el feminicidio como delito autónomo, junto con el tipo penal de lesiones personales con el uso de químicos o sustancias corrosivas.

La punitividad, punitividad populista o populismo penal, como fenómeno social, se define como el movimiento político que, por medio de una oratoria persuasiva, establece canales de comunicación especial con un determinado grupo de personas representado por un líder que orienta hacia a un objetivo social principal. A partir de las clases de comportamientos punitivos se pueden construir conceptos que evidencien una posición ante los problemas normativos, los cuales se plantean como herramientas de análisis de las leyes que se abordarán a continuación para determinar su impacto en la política penal.

Todo inicia con la Ley 1761 de 2015, en la que se tipifica el tipo penal de feminicidio:

Quien causare la muerte a una mujer, por su condición de ser mujer o por motivos de su identidad de género o en donde haya concurrido o antecedido cualquiera de las siguientes circunstancias, incurrirá en prisión de doscientos cincuenta (250) meses a quinientos (500) meses. ${ }^{1}$

Esta Ley fue impulsada debido al doloroso caso de Rosa Elvira Cely, quien fue víctima de tortura, acceso carnal violento agravado y, como si fuera poco, homicidio agravado. Fue un evento muy conocido en Colombia, ocurrido en Bogotá, por el atroz acto cometido contra una mujer. Gracias a la indignación de las personas solidarias con ella y su familia se propuso un proyecto de ley que tenía como objetivo la tipificación del feminicidio y, tiempo después, se convirtió en la ley que es utilizada para apoyar veredictos en casos en lo que se implica el problema de género y la agresión contra las mujeres. Respecto a los análisis de las agresiones físicas, psicológicas y verbales por motivos de género, se tenía como fin examinar la posibilidad de que hubiera una intervención del Estado en materia penal, para que existiera la necesidad de criminalizar el feminicidio y aumentar las penas coactivas que obligaran al agresor a pagar las consecuencias de su conducta.

1 Rafael Velandia Montes, Del populismo penal a la punitividad: la política penal en Colombia en el siglo XXI (Bogotá: Universidad Católica de Colombia, 2017), 27. 
Surge la siguiente pregunta: ¿Es necesaria la criminalización del feminicidio? Se considera equivocado pensar que el feminicidio es una conducta punitiva que rechaza la violencia sistemática de la cual son víctimas las mujeres por el hecho de ser mujeres; se justifica una herramienta diferente a la del homicidio, ya que el sistema está en la obligación de reconocer su gravedad y castigarlo como un tipo penal autónomo. De tal manera, de acuerdo con lo planteado, la respuesta es negativa y se propone una revisión de los argumentos expuestos en el proyecto de ley.

Es increíble que Colombia sea uno de los lugares donde las mujeres son violentadas del modo más inhumano, donde son vulnerados sus derechos y su humanidad tanto física como emocional, a tal punto que el agresor acaba con la vida de su víctima. Se habla ahora de la violencia letal y no letal en contra de la mujer en Colombia por motivos de género. El crimen más perpetrado es el que se comete contra las mujeres por el simple hecho de ser mujeres, por lo que deja de ser un homicidio y se tipifica como feminicidio, ya que ese término va directamente asociado con las mujeres. ¿Es esto posible? Sí; tal parece que en Colombia todo es posible. La indignación de la sociedad — tanto de mujeres como de algunos hombres— reclama por una pena justa hacia los "agresores", asesinos, violadores o inhumanos, como se les llama, sigue a la espera, a pesar de que existe una pena para ellos. Colombia es un país conservador, en el que se delimitan las tareas que le corresponden a cada género (hombres y mujeres). También se considera un país machista, debido a que la mujer era tratada como un ser inferior al hombre "porque así debía ser" y, en la actualidad, se continúa discriminándola por el simple hecho de ser mujer, por ejemplo, respecto al sueldo que gana en sus trabajos, comparado con el que gana el hombre o respecto a la forma de evaluar sus capacidades para obtener un empleo; es un pensamiento absurdo, ya que a medida que ha pasado el tiempo, la concepción de la mujer ha cambiado y ya no se ve como un objeto o un ser inferior. Hoy en día, hombres y mujeres tienen iguales derechos y obligaciones; por tanto, deben recibir el mismo trato y las mismas oportunidades.

En tema de género, la Ley 1773 de 2016 y el Artículo 116A de la Ley 599 de 2000 establecen las lesiones con agentes químicos, como los ácidos o las sustancias químicas que causen algún daño brutal en la salud. Este tipo de actos criminales causan daños irreparables a la víctima y son cometidos con mayor frecuencia hacia mujeres. Estos actos criminales son cometidos con el fin de causar daño físico, pero más allá de las heridas, el agresor busca provocar un daño moral, ya que es un acto irreversible. 
En casos como las agresiones o los atentados hacia las mujeres, el derecho comparado no es el único instrumento que se puede utilizar para solucionarlos, puesto que para las víctimas de estos ataques que han recurrido al sistema judicial colombiano es vital que estos hechos no queden en la impunidad y pueda ponerse un alto a todos aquellos eventos en los que las mujeres son vulneradas y haya reparación por los daños causados.

Ya que hoy en día la mujer tiene voz y voto y llegó el momento de erradicar por completo los problemas o las confrontaciones de género, que el empoderamiento de la mujer sea símbolo — no solo personal, sino también conjunto— para seguir implementando leyes que protejan sus derechos y acaben con la impunidad.

Alejandra Hernández C.

* $\quad$ Estudiante de Derecho, Universidad Católica de Colombia. 